\title{
Shame and simplicity in Afghanistan
}

$\mathrm{W}$

hile working in Kabul this past November, I had an enlightening conversation with an Afghan doctor, an intelligent man who excelled in his work with international organizations and had recently moved from a remote village to Kabul. He told me about the birth of his son and how he had acquiesced to family demands and recommendations from international colleagues that his expectant wife seek care from a doctor.

After settling into the maternity ward, her labour stopped and did not restart by nightfall. His suggestion that she remain in hospital was met with scorn: "I refuse to give birth in this filthy hospital! Take me home!" she cried. In the privacy of their home his mother boiled string and gauze and his wife happily gave birth, surrounded by a loving family. I sympathized with her. Given the contrast between Afghan homes and hospitals, I would have done the same.

The story came after a discussion about community-oriented strategies to address maternal and child health. I lamented the vast resources invested in facility-based care when women valued delivering at home.1 Most funded activities involve training midwives and doctors. Training uneducated village women, who have facilitated deliveries for centuries, remains unpopular in Afghanistan. Yet the fact is, untrained lay women continued to deliver more than $80 \%$ of babies, even in 2007 after 1864 midwives had graduated.2 Rather than build on existing village resources, we simply imposed our Western values and announced that women would seek care from doctors or midwives. At the same time we supported a new cadre of health volunteer: community health workers, who we advise not to attend deliveries. However, like villagers everywhere, they follow local rules.

During my sixth visit to Afghanistan, I focused on improving the monitoring of the basic package of health services provided by community health workers. Their challenges were discussed in a workshop that left me frustrated by the blindness educated urbanites seemed to show for village politics and the futility of using financial incentives to motivate community health workers to do our bidding. I wanted to cry out, "How about inspiring them by helping them to successfully accomplish what is valued in their communities: bringing healthy newborns into the world and saving women's lives?" They were doing it anyway.

Simple, reality-based solutions seemed to have been forgotten. Training community health workers in "hygienic" deliveries, for example, would be highly appropriate. It could potentially mitigate existing harmful practices and promote useful ones. Since 20000 community health workers are already trained to provide basic health information and services, schooling them in the correct basic care of expectant mothers seemed logical. Granted, such training is a temporary measure in a resource-poor setting with insecurity and a destroyed health system, where maternal and neonatal mortality are huge. But it is doable. Unfortunately, it's against a Ministry of Public Health policy spearheaded in 2002 by international organizations, which promoted well-intentioned goals while being seemingly oblivious to the extreme poverty, remarkable illiteracy rates, neophyte government, predominantly rural population, insecurity and foreign cultural rules.

Several years later, the problem with the policy is evident - few trained doctors and midwives provide obstetric care in rural areas where more than $75 \%$ of women live. ${ }^{3}$ Educated people don't fit in villages where life remains suspended between the dawn of Mohammad (Peace be upon Him) and the 18th century. Untrained women still have the responsibility of assisting births in settings where maternal mortality is highest: 1200 to 6400/100 000 live births. ${ }^{4}$

Improving this situation requires that Afghans define the situation realistically and the international community listens, then helps to design and implement simple, reality-based solutions. What's

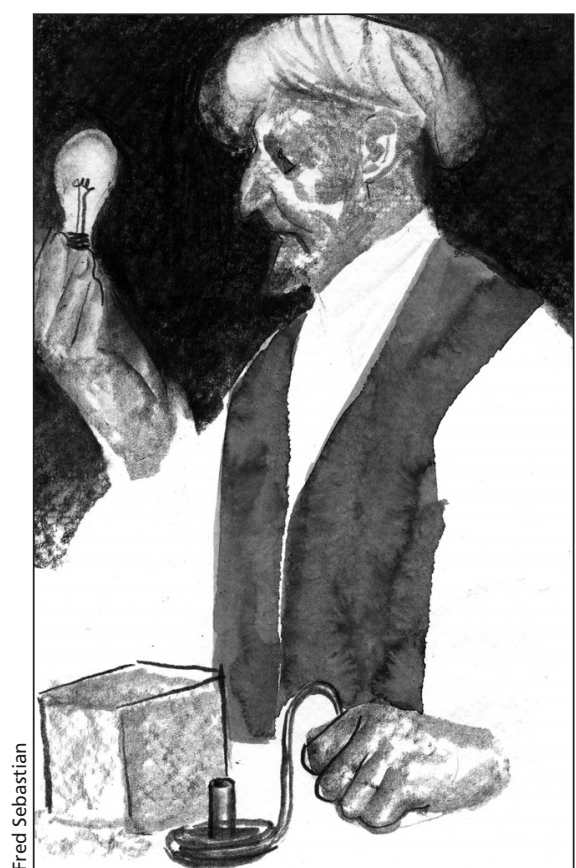

needed is large-scale implementation of low-technology, simple solutions in rural areas where the majority of the population lives and a plan for stepwise improvements to eventually achieve international standards. Defining reality and maintaining simplicity are too often forgotten prerequisites for success in such a challenging environment.

\section{Maureen Mayhew MD MPH \\ Technical Consultant \\ Tech Serve International \\ Vancouver, BC}

\section{REFERENCES}

1. Afghan Ministry of Public Health. Afghanistan national health services performance assessment: results of formative research. Kabul: The Ministry; 2005.

2. Afghan Ministry of Public Health. Afghanistan health survey 2006 - estimates of priority health indicators for rural Afghanistan. Kabul: The Ministry; 2006.

3. UNICEF. Best estimates of social indicators for children in Afghanistan. New York: UNICEF; 2005.

4. Bartlett LA, Mawji S, Whitehead S, et al. Where giving birth is a forecast of death: maternal mortality in four districts of Afghanistan, 1999-2002. Lancet 2005;365:864-70.

Have you got an opinion about this article? Post your views at www.cmaj.ca. Potential Salon contributors are welcome to send a query to salon@cmaj.ca. 